\title{
Structural assessment of a masonry vault in Portugal
}

\author{
Pedro Lança ${ }^{1 \dagger}$, Paulo B. Lourenço ${ }^{2}$, Bahman Ghiassi ${ }^{3}$ \\ ISISE, University of Minho, Department of Civil Engineering, Guimarães, Portugal
}

\begin{abstract}
This paper addresses the safety assessment and the performance evaluation of the High Choir of the Santa Maria de Belém Church, in the Jerónimos Monastery, Lisbon, which is the crown jewel of cultural heritage buildings in Portugal. The possibility of adding a new 20-ton organ to the high choir, and its effects on the structural response, are presented. A refined and simplified finite element model is developed to investigate the structure performance under its own weight and seismic actions. A sensitivity analysis is performed to investigate the effect of masonry mechanical properties and ribs' cross-sections on the structural response (due to the difficulty on obtaining these information). The results show that the safety level of the structure is acceptable, even in the case of adding the rather heavy new organ.
\end{abstract}

Keywords: Masonry; Vaults; Safety assessment; Numerical modeling; FEM; Pushover

${ }^{1} \mathrm{MSc}$ Student, ISISE, University of Minho. He was appointed as a faculty member of Polytechnic Institute of Beja, Portugal and left us unexpectedly. He was a young engineer specialist in conservation of historic buildings and with a sincere passion for research and education.

${ }^{2}$ Professor, ISISE, University of Minho, Department of Civil Engineering, Azurém, 4800-058

Guimarães, Portugal. Phone: +351 253510 209, fax: +351 253510 217, E-mail:

pbl@civil.uminho.pt

${ }^{3}$ Postdoctoral researcher, ISISE, University of Minho, Department of Civil Engineering, Azurém, 4800-058 Guimarães, Portugal. Phone: +351 253510 499, fax: +351 253510 217, E-mail: bahmanghiassi@civil.uminho.pt 


\section{Introduction}

Traditional masonry buildings and cultural heritage buildings are vulnerable to dynamic actions, such as earthquakes. Severe damage, and in some cases, structural collapse have been observed in past earthquakes, stressing the need for the safety assessment and evaluation of these buildings (Lagomarsino, 2006). The seismic vulnerability of historical masonry buildings is known to be due to materials' mechanical properties (e.g. low tensile strength, heavy weight, and heterogeneity of the masonry), and to particular structural configurations (e.g. slender walls, weak connections, and large openings) (Betti and Vignoli, 2008; Lourenço, 2002).

The safety assessment of historical constructions is quite a complex task, since little is usually known about the structure and the materials' properties. Variability of mechanical properties through the structure, existing damage and deterioration, and the constitution of the inner core of the elements, are also among the encountered problems (Binda et al., 2000; Lourenço, 2002; Betti and Vignoli, 2011; Asteris et al., 2014). Moreover, each cultural heritage building is unique, with its own history, often with specific structural and non-structural changes, which strongly affect its seismic performance (Betti and Vignoli, 2011). Several advances have been made over the past few years in the modeling and analysis of historical structures. Advanced material models have been implemented in computational tools, and different methodologies have been proposed for the seismic assessment of historical masonry (Lourenço and Mourão, 2001; Giordano et al., 2002; ICOMOS, 2005; Casarin and Modena, 2008; De Luca et al., 2008; Roca et al., 2010).

This study aims at the safety assessment of the vaults of the High Choir of the Monastery

of Jerónimos, Lisbon, using the Finite Elements Method (FEM). The Monastery of Jerónimos is a notable example of the Late Gothic Manueline architectural style, of the sixteenth century 
(Lourenço and Mourão, 2001; Genin, 2001). The structure suffered some damage in 1776, in the aftershock of the large Lisbon earthquake, while several changes and repairs were done during the nineteenth century. The high Choir consists of six ribbed vaults, supported by walls and Tudor arches. The effect of this addition on the safety of the vault, and on the seismic performance of the structure, remains an open issue, and is the subject of this study. The possibility of adding a new organ, with a total weight of 20 tons, and its effects on the structural safety is also investigated.

The low tensile strength of the material limits the applicability of linear elastic analysis for masonry structures. Modal superposition in dynamic analysis is, therefore, not applicable, while time-integration methods are time-consuming and complex in large engineering problems, as is the case of this study. Nonlinear static analysis is therefore chosen here. The most critical vault, in which the new organ will be located, is modeled and investigated in this study.

Two different modeling strategies are followed: refined and simplified models. The latter can be considered as an important contribution to the present paper, demonstrating the feasibility of using simplified models for the analysis of complex monumental structures. The first model, denoted as a refined model, consists of solid three-dimensional elements, while the second model, denoted as a simplified model, is constructed with beam and shell elements, resulting in a significant reduction in the analysis time.

The modeling was done in two stages. In the first stage, a refined model and a simplified model of the main vault of the structure were produced. The deformation and displacements of the model under its self-weight were compared, to investigate the reliability of the simplified model. After initial validation, at the second stage, the simplified model was used for the assessment of the safety of the High Choir under its own weight and seismic actions. Due to the 
lack of information regarding the material mechanical properties, and the ribs' structural geometry, a sensitivity analysis was also performed on the effect of these properties on structural response. The results showed that the safety level of the structure remained acceptable, even in case of adding the new organ.

\section{High Choir of the Santa Maria de Belém Church}

\subsection{Architectural and Historical survey}

The Monastery of Jerónimos is probably the main asset of Portuguese architectural heritage, and dates from the sixteenth century. The construction planned initially by Diogo Boitaca was gigantic (four times the size of the actual monastery), including four cloisters and four dormitories. In fact, only one dormitory and one cloister were completed. The monastery is built in limestone (usually denoted by "lioz" type) quarried locally. The construction of the monument was carried out in three successive phases during the sixteenth century. The works in the seventeenth and eighteenth centuries were merely decorative or minor. In the nineteenth century, questionable restoration actions were carried out, and in 1940, an attempt to correct previous mistakes and return the monastery to its original configuration was made. The monumental set has considerable dimensions in plan, of more than $300 \times 50 \mathrm{~m}^{2}$, and an average height of $20 \mathrm{~m}$ (50 $\mathrm{m}$ in the towers); see Fig. 1. The monastery revolves around two courts. The larger court is bordered by a long arcade of two levels that host the Ethnographic Museum of Archaeology, and the Maritime Museum. The smaller court or the cloister is bordered by the church, the Sacristy, the Chapter Room and the Refectory.

The Gothic style was introduced more recently in Portugal, incorporating a specific national influence. The so-called "Manueline" style (after King D. Manuel I), exhibits a large 
variety of architectural influences and erudite motives. An interesting aspect of the style appears in the sixteenth century, when traditional three-nave churches were replaced by a configuration with small differences in the naves' height. In the church of the Monastery of Jerónimos, the vault springs from one external wall to the other, supported by thin columns that divide the naves almost imperceptibly. The fusion of the naves in the present church is more obvious than in other manifestations of spatial Gothic. For this purpose, arches are no longer visible, the slightly curved vault comprises a set of ribs, and the fan columns effectively reduce the free span. Additional information about the church and its architectural aspects can be found in Genin (2001).

The structure resisted well the 1755 earthquake, but another earthquake in late 1756 resulted in the collapse of one of the church's columns that supported the vaults of the nave. The collapse of the column led to the partial damage and collapse of the nave. The vault of the high choir also partially collapsed during this earthquake. Several changes and repairs were made to the structure of the monastery during the nineteenth century, including the structure of two towers, the roofs, and the vaults.

\subsection{High Choir}

The High Choir is located at the entrance of the church, along the first two sections. The first section occupies the space between the two adjoining rooms, located beneath the primitive towers, and the second one accompanies the width of the nave (see Fig. 1). The ceiling of the Choir consists of six similar ribbed vaults, supported by walls, Tudor arches, and two columns of stone masonry (see Fig. 2). The new organ will be supported by the vault located in the southeast 
of the structure (the same location as the old organ). This vault is therefore modeled in this study as the most critical vault in the High Choir; shaded in Fig. 2(a).

The vault has a rectangular shape, and approximate dimensions of $5.50 \times 8.60 \mathrm{~m}^{2}$. The geometrical details of the vault were obtained by on-site measurements, due to the lack of detailed information. The vault is surrounded by two walls to the south and west, and two Tudor arches to the north and east, as shown in Fig. 3. The wall in the south façade is continuous along the structure, and has a constant thickness of about $1.90 \mathrm{~m}$. The wall has three buttresses with trapezoidal elevations to ensure its stability (see Fig. 1). The west wall, located next to the baptismal chapel, has a thickness of about $1.90 \mathrm{~m}$, which is reduced to $0.70 \mathrm{~m}$ along the existing niche (see Fig. 3(b)).

The two columns of the High Choir have identical cross-sections and boundary conditions, and are braced transversely at the level of the vaults (see Fig. 4(a)). The column P1 has a complex cross-section with maximum dimensions of about $2.80 \times 2.60 \mathrm{~m}^{2}$, see Fig. 4(b), which has been approximated, with a rectangular section $(2.4 \times 2.1 \mathrm{~m})$ for simplification of the modeling process. Above the High Choir, the columns have an octagonal section that can be approximated as a circle, with a diameter of 1.04 m (Lourenço and Krakowiak, 2004).

The arches at the boundaries of the vault have different cross-sections (see Fig. 5). The east arch has an L-shaped cross-section, and the distance between the supports is $4.0 \mathrm{~m}$. The north arch has dimensions of about $1.22 \times 1.09 \mathrm{~m}^{2}$, and the distance between the supports is $6.2 \mathrm{~m}$. The thickness of the arch is obtained as the distance between the intrados of the arch and the extrados of the adjacent ribs. The cross-sections of the arches are also approximated with rectangular sections, as shown in Fig. 5. Although the L-shaped cross-section for the east arch is 
poorly approximated, the results are conservative, and therefore the approach is assumed to be acceptable.

The vault is made of 0.1 m-thick stone slabs, which are supported on stone ribs. A filler layer with varying thickness is used over the slabs. The thickness of the filler layer is obtained as the distance between the upper surface of the stone slabs and the paving of the High Choir. It therefore changes from $0.5 \mathrm{~m}$ to $2.0 \mathrm{~m}$ to form the supports to the vault key.

The plan of the ribs is presented in Fig. 6(a). The ribs have two different cross-sections, called N1 and N2, as shown in Fig. 6(b). The shaded ribs in Fig. 6(a) are N1 type, and the rest are N2. The ribs' cross-sections are approximately modeled with trapezoidal and rectangular shapes, as shown in Fig. 6(c).

\section{Finite Element Analysis}

The safety assessment of the High Choir is performed through numerical modeling, using the FE code DIANA (2009). A simplified model (using beam and shell elements) is produced to investigate the performance of the structure under its own weight and lateral loads (seismic loads).

The modeling is performed at two different stages. The first stage includes modeling (only) the vault for the validation of the simplified modeling strategy. A refined and a simplified model are thus produced, with the assumption that the vault is simply supported on its edges, and the vertical deformations obtained from both models are compared.

Once the simplified modeling strategy is validated, it is used in the second stage to produce the model of the High Choir structure (including the vault, column, and walls), to investigate its performance. 


\subsection{FE model}

The refined model of the vault consists of 20-node and 15-node, three-dimensional solid elements (labeled as CHX60 and CTP45 in DIANA), used for modeling the ribs, the slabs, and the filler layer (see Fig. 7). As explained before, the refined model is used for modeling the vault structure, and the walls and columns are not modeled at this stage. The simplified model of the vault consists of three-dimensional curved beam elements (labeled as CL18B in DIANA), used for modeling the slabs and ribs (see Fig. 8).

The High Choir model consists of three-dimensional curved beam elements (labeled as CL18B in DIANA), and quadratic curved shell elements (labeled as CQ40S in DIANA). The slabs, ribs, and the column P1 are modeled using the beam elements, while the walls and buttresses are modeled with shell elements. The existing opening in the south wall, and the thickness reduction in the west wall (at the niche), are not considered in the numerical model. The influence of these openings on the performance of the vault is negligible, and this simplification does not affect the numerical results.

The bases of the walls and the column are fully fixed (against rotations and displacements) in the numerical model. The rotation at the bases, as is not constrained in reality, is released automatically in the analysis, due to the assumed nonlinear material model, and zero tensile strength for the masonry. The horizontal displacements of the vault at the boundaries with adjacent vaults (at north and west) are restricted (see Fig. 9). The transverse displacement of the column head along north, is also restricted to ensure the compatibility of the displacements between the column and the vault. 
The cross-sections of the ribs, arches and columns are approximated in both the refined and simplified models, for the simplification of the modeling process (as explained before); see Fig. 4-6.

\subsection{Materials}

Two different material properties are considered for the stone masonry (Young modulus $E=3000 \mathrm{MPa}$, compressive strength $f_{\mathrm{c}}=3.0 / \mathbf{6 . 0} / 9.0 \mathrm{MPa}$ and zero tensile strength), and the filler layer ( $E=500 \mathrm{MPa}, f_{\mathrm{c}}=1.0 \mathrm{MPa}$ and zero tensile strength). Given the uncertainty about the mechanical properties, a sensitive analysis is carried out on the compressive strength of the stone masonry, assuming $f_{\mathrm{c}}=6.0 \mathrm{MPa}$ as the reference value. The effect of the filler's compressive strength on the structural response was observed to be negligible in Lourenço et al. (2007), and therefore is taken as $1.0 \mathrm{MPa}$ in this study. A total strain-rotating crack model, with an idea plastic compression limiter, are adopted for the materials, to simulate the nonlinear behavior and cracking distribution (DIANA, 2009).

\subsection{Loads}

The loads considered in the analysis include vertical (the actual weight of the structure, and the new organ) and lateral (for performing the pushover analysis) actions.

The specific weights adopted for stone masonry and the filler material are $22 \mathrm{kN} / \mathrm{m}^{3}$ and $18 \mathrm{kN} / \mathrm{m}^{3}$, respectively. The roof dead load is simulated by an equivalent, uniformly distributed load of $0.3 \mathrm{kN} / \mathrm{m}^{2}$ (see Lourenço et al., 2007). The weight of the column above the High Choir and the roof, supported by the column, is simulated by the application of a point load ( $2400 \mathrm{kN})$ at the top of the column (Lourenço et al., 2007). The self-weight of the walls above the High 
Choir, and the structure supported by them, is simulated by means of uniform loads, applied to the top of the walls $(737.6 \mathrm{kN} / \mathrm{m}$ for the south wall, and $797.3 \mathrm{kN} / \mathrm{m}$ for the west wall). The vertical loads, due to the new organ, are applied as three different bodies of $1.5,12$ and 6 tons, resulting in a total 19.5 tons.

As an alternative to the more complex and time-consuming methods, such as the time history Eurocode $8(\mathrm{EC} 8,2004)$ proposal, a nonlinear static analysis (push-over) is performed in this study, to investigate the response of the structure to vertical and horizontal actions. The incremental static loads are applied proportional to the mass of the structure and the new organ (distributed based on the dead loads), and in the most unfavorable direction (see Fig. 9). The static forces are obtained by multiplying the loads corresponding to the mass, by a seismic coefficient value equal to 0.22 , according to the Portuguese standard (RSA, 1983). This value is in the proposed range of seismic coefficient for historic buildings in high seismicity areas (between 0.1 and 0.3), according to Meli (1998).

\section{Validation of the simplified model}

The validation is performed by comparing the obtained vertical deformation of the vault (under its self-weight) in the refined and simplified models. Here, the slabs are assumed to be simply supported at the boundaries for validation of the simplified model, as only the vault is considered in both models (i.e. without the vertical supporting elements).

The analysis is performed under different self-weight conditions. As an example, the deformation of the slab, under total self-weight (ribs, slabs and filler layer), is presented in Fig. 10 for both models. The vault maximum vertical deformation, $\delta_{z, \max }$, in both models is summarized in Table 1, for all the considered cases. A difference smaller than $20 \%$ is found 
between the vertical displacements of the slabs, in the refined and the simplified models, for all the analyses. Given the large uncertainties of geometry and material properties in the structure under study, the observed difference is acceptable, and the simplified model can be adopted. Moreover, the results from the simplified model are larger, and therefore conservative when the total self-weight is considered, as is also the case for the pushover analysis.

\section{Nonlinear analysis}

The nonlinear analysis of the structure is performed on the simplified model at two stages, by performing pushover analysis based on the distribution of the mass in the structure. In the first stage, the nonlinear behavior of the structure, under its self-weight (with and without considering the weight of the new organ), is assessed. Then, the analysis is continued by a pushover analysis, assuming both material and geometrical nonlinearities. Due to the lack of information on the masonry compressive strength, and the exact cross-section of the ribs, a sensitivity analysis is performed on the effect of these factors on the structure's performance. The reference material properties, used initially in the analysis, are $f_{\mathrm{c}}=6 \mathrm{MPa}$ for the stone masonry, and $f_{\mathrm{c}}=1 \mathrm{MPa}$ for the filler layer. Since the nonlinear behavior and safety evaluation of the vault are the main objectives of this study, a linear behavior is assumed for the walls and buttresses (shell elements). The reference cross-section of the ribs are the observable cross-sections, shown in Fig. 6. However, it is possible that the ribs are extended through the slabs' thickness, which can affect the structural performance significantly. This possibility has been also investigated in the sensitivity analysis.

The results of the pushover analysis are presented in terms of load factor-displacement curves, at critical sections of the structure. The load factor is defined as the ratio of the applied 
load in each step to the total load, and therefore can be assumed as the safety factor of the structure. The crack distributions at the extrados and intrados of the vault are also presented, and discussed for different loading conditions.

\subsection{Self-weight analysis}

A nonlinear pushover analysis is performed initially on the structure under its self-weight (with and without considering the weight of the new organ).

As an example, Fig. 11 and Fig. 12 present the results obtained for the reference model under the self-weight (without considering the new organ). Fig. 11 (a) shows the pushover curve of the structure at the vault key and the column head. It can be observed that the response of the structure is nonlinear at the vault key, while the column behavior is linear. The safety factor of the structure (load factor) at failure is 5.0, which is rather large considering the partial safety coefficient for material $\left(\gamma_{M}=2.5\right)$, and for the loads $\left(\gamma_{M}=1.35\right)$, with the result of $3.4(2.5 \times 1.35)$, according to Eurocode 0 (EC0, 2002) and Eurocode 6 (EC6, 2005).

The failure occurs due to the large vertical deformation at the key $(68 \mathrm{~mm})$; see Fig. 11(b). A large horizontal displacement also occurred at the column head (8 $\mathrm{mm}$ at failure load). This horizontal shift directly affects the balance of the north arch, and results in increment of the arch vertical deformation, and the out-of-plane movement of the west wall (in x-direction). This out-of-plane movement is about half of the horizontal displacement of the column (in ydirection). The vertical deformation of the column, due to the self-weight of the structure, is equal to $6.0 \mathrm{~mm}$ at the ultimate load step.

The principal strains and stresses at the intrados and extrados of the vault at the ultimate load stage are shown in Fig. 12. The principal tensile strains developed at the intrados. Fig. 12(a) 
shows significant cracking in the diagonal ribs supported by the south wall (center) and the north arch, and occasionally, in the ribs around the central hexagon. There is also significant cracking in the closure zone of the two arches (north and east). At the extrados (Fig. 12(b)), the cracks are extended along the ribs that are supported by the central region of the south wall and the north arch. There is also moderate to significant cracking in the east and west arches.

The principal compressive stresses at the intrados of the vault are presented in Fig. 12(c). High compressive stresses developed at the vertices of the central hexagon, while moderate stresses are observed in the diagonal ribs around the vault corners. The compressive stresses at the vault extrados (Fig. 12(d)), are commonly located at the central hexagon and some peripheral ribs. Moderate compressive stresses can also be observed at the ends of the two arches.

The effect of masonry compressive strength on the vault behavior (under its self-weight) is shown in Fig. 13. It can be seen that the safety factor is about 3.4 when $f_{\mathrm{c}}=3.0 \mathrm{MPa}$, and this increases to 5.5 when $f_{\mathrm{c}}=9.0 \mathrm{MPa}$; all higher than the total safety given above. The horizontal displacement of the column remains elastic in cases of $f_{\mathrm{c}}=6.0 \mathrm{MPa}$ and $f_{\mathrm{c}}=9.0 \mathrm{MPa}$, but it becomes slightly nonlinear when the compressive strength is assumed to be equal to 3.0 MPa.

The self-weight analysis is also performed considering the weight of the new organ, in addition to the structure's own weight. The load-displacement curves of the structure with different masonry compressive strengths are shown in Fig. 14 for this case. It can be observed that the response of the structure is highly nonlinear at the vault key. The safety factors, being less than the latter case, are 3.0, 4.0 and 4.5, in the cases of $f_{\mathrm{c}}=3.0,6.0$ and 9.0 MPa, respectively. The safety factors again seem acceptable in the context of an existing structure, where safety factors can be slightly lowered. The vertical deformation of the column remains linear after 
adding the weight of the new organ, but its horizontal deformation becomes highly nonlinear in the case of $f_{\mathrm{c}}=3.0 \mathrm{MPa}$.

The sensitivity of the structural response to the cross-section of the ribs is presented in Fig. 15. Contrary to the reference cross-sections (see Fig. 6), it is assumed here that the ribs are extended until the extrados of the vault, as shown in Fig. 15(a). It can be seen that the influence of this change is significant on the structural response (see Fig. 15(b)). The safety factor increases from 5 in the reference model, to 6 in the model with the ribs' extended cross-sections.

\subsection{Pushover analysis}

The pushover analysis is performed in combination with the structure's self-weight for different masonry compressive strengths. The lateral loads are applied, based on the distribution of the mass of the structure (vault, walls and pier), as explained in Section 3.3. The load of the new organ is assumed as:

The results are shown in Fig. 16 and Fig. 17, in terms of force-horizontal displacement of the north arch and the column head.

Fig. 16 presents the structure behavior when only the self-weight is considered in the analysis. It can be observed that the response is severely nonlinear at the arch and the column head. The masonry compressive strength significantly affects the structural response, resulting in the change of safety factor from 2.0 to 4.5 , when masonry compressive strength changes from 3.0 to $9.0 \mathrm{MPa}$ (around 4.0 in the reference model). The safety factor of the structure is acceptable, considering the earthquake as an accidental action, which results in a partial safety coefficient of materials as $\gamma_{M}=1.5$, and for the loads as $\gamma_{M}=1.5$, with the result of $2.25(1.5 \times 1.5)$. 
Only in the case of $f_{\mathrm{c}}=3.0 \mathrm{MPa}$ is the safety factor (2.0) slightly less than the total partial safety coefficient, which again is deemed as acceptable for an existing structure.

The numerical pushover curves, for the cases in which the weight of the new organ is also considered in the self-weight of the structure, are presented in Fig. 17. Here, the safety factors are 2.0, 3.2 and 4.0, for masonry compressive strengths of 3.0, 6.0 and 9.0 MPa, respectively. Again the structure safety level is acceptable.

The principal strains and stresses, developed at the ultimate load stage at the vault extrados and intrados, are shown in Fig. 18 , for the reference model $\left(f_{\mathrm{c}}=6.0 \mathrm{MPa}\right)$. At the intrados (see Fig. 18(a)), significant cracking can be observed in the diagonal ribs supported on the south wall, in the central region of the arch and under the new organ. At the extrados (see Fig. 18(b)), the cracks are distributed in the ribs supported by the south wall (central region) and arches. Some cracking can also be observed near the column.

Fig. 18(c, d) show a concentration of high compressive stresses in the central region of the vault and adjacent ribs. Moreover, moderate compressive stresses are developed in the ribs supported by the south and north walls. In the extrados vault, high compressive stresses are developed in the central region and under the new organ, as well as near the column support, and the boundaries of the north and east arches.

The sensitivity of the structural response to the cross-section of the ribs is also investigated and the results are presented in Fig. 19. In this case, the cross-section has a moderate effect on the structure safety factor. The safety factor has increased from 3.2, in the reference model, to 3.5 , in the model with ribs with extended cross-sections. 


\section{Conclusions}

A seismic assessment and structural performance of Gothic stone vaults, in particular, the High Choir of the Church of Santa Maria de Belém in Jerónimos Monastery, were investigated in this paper. The safety level of the structure was investigated numerically under its self-weight and seismic actions. Since the organ of the church has been removed, the possibility of placing a new tube organ, with a total weight of 20 tons, and its effects on the structural response, were also investigated. The High Choir consists of six similar ribbed vaults. The most critical vault, in which the new organ will be located, was modeled and investigated in this study. A simplified model (using beam and shell elements) was produced, to investigate the performance of the structure under its self-weight and lateral loads (seismic loads).

The modeling was performed at two different stages. The first stage included modeling (only) the vault for validation of the simplified modeling strategy. A refined and a simplified model were thus produced, with the assumption of the vault being supported simply on its edges, and the vertical deformations obtained from both models were compared. Once the simplified modeling strategy was validated, it was used at the second stage to produce the model of the High Choir structure (including the vault, column and walls), and investigate its performance.

The refined model consisted of solid three-dimensional elements, while the simplified model was constructed with beam and shell elements, resulting in a significant reduction of the analysis time. The structural response was studied by performing a nonlinear static analysis (pushover) under horizontal and vertical loads. The dead load of the structure consisted of the dead load of the materials and structural elements, as well as the new organ and resulting loads from the roof. The pushover analysis was performed by applying static forces, distributed based on the mass of the structure. Lack of information about the mechanical properties of stone 
masonry and the ribs' geometry led to a parametric analysis, to investigate the effect of these factors on the structural response. Both cases, particularly the first one, resulted in significant changes in the structural response.

The results reveal that the safety factor of the structure remains acceptable in all cases, under the combined actions of the self-weight, the new organ, and an earthquake. In general, the failure mechanisms of the high choir at the last load stages were due to the exessive horizontal displacement of the column head, and cracking of the central region of the dome, and the north and east arches. The supporting column seems to be the most important structural element in establishing the safety of the structure. Its safety factor at failure was about 3.2 in the reference model $\left(f_{\mathrm{c}}=6.0 \mathrm{MPa}\right)$, under the combined action of the self-weight (dead load and new organ) and earthquake, which was found to be acceptable.

\section{References}

Asteris PG, Chronopoulos MP, Chrysostomou CZ, Varum H, Plevris V, Kyriakides N and Silva V (2014) Seismic vulnerability assessment of historical masonry structural systems. Engineering Structures 62-63:118-134.

Betti M and Vignoli A (2008) Modeling and analysis of a Romanesque church under earthquake loading: Assessment of seismic resistance. Engineering Structures 30(2):352-67.

Betti M and Vignoli A (2011) Numerical assessment of the static and seismic behaviour of the basilica of Santa Maria all'Impruneta ( Italy ). Construction and Building Materials 25(12):4308-24.

Binda L, Saisi A and Tiraboschi C (2000) Investigation procedures for diagnosis of historic masonries. Construction and Building Materials 14:199-233.

Casarin F and Modena C (2008) Seismic assessment of complex historical buildings: application to Reggio Emilia Cathedral, Italy. International Journal of Architectual Heritage 2:304-27. 
De Luca F, Verderame GM and Manfredi G (2014) Eurocode-based seismic assessment of modern heritage RC structures: The case of the Tower of the Nations in Naples (Italy). Engineering Structures 74(1):96-110.

DIANA 9.4 (2009) Displacement method Analyser, release 9.4, User's Manual. TNO DIANA Bv: The Netherlands.

EC0. Eurocode 0 (2002) Basis of structural design, CEN.

EC6. Eurocode 6 (2005) Design of masonry structures, Part 1-1: General rules for building: rules for reinforced and unreinforced masonry structures, CEN.

EC8. Eurocode 8 (2004) Design of structures for earthquake resistance,Part 1: general rules, seismic actions and rules for buildings, CEN.

Genin S (2001). The nave vault of the Hieronymites Monastery Church in Lisbon. In The third international seminar on historical constructions. Guimaraes, pp. 293-302.

Giordano A, Mele E and De Luca A (2002) Modeling of historical masonry structures: comparison of different approaches through a case study. Journal of Engineering Structures 24:1057-69.

ICOMOS (2005) Recommendations for the analysis, conservation and structural restoration of architectural heritage, Paris, France.

Lagomarsino S (2006) On the vulnerability assessment of monumental. Bulletine of Earthquake Engineering 4:445-63.

Lourenço PB (2002) Computations on historic masonry structures. Progress in Structural Engineering and Materials 4:301-19.

Lourenço PB, Krakowiak KJ, Fernandes FM and Ramos LF (2007) Failure analysis of Monastery of Jero: how to learn from sophisticated numerical models. Engineering Failure Analysis 14:280-300.

Lourenço PB and Krakowiak KJ (2004) Stability of the vaults in the Monastery of Jerónimos Church [in Portuguese]. In Computational Methods in Engineering, Lisbon.

Lourenço PB and Mourão S (2001) Safety assessment of Monastery of Jerónimos, Lisbon. In Historical Constructions (Lourenço PB and Roca P (eds.)). Guimarães, pp. 697-706.

Meli, R (1998) Structural Engineering of Historical Buildings [in Spanish],

Roca P, Cervera M, Gariup G, and Pela' L (2010) Structural analysis of masonry historical constructions. Classical and Advanced Approaches. Archives of Computational Methods in Engineering 17(3):299-325. 
RSA, 1983. Portuguese regulations for the safety and actions for structural buildings and bridges. 


\section{List of Tables}

Table 1. Adopted mechanical properties for numerical models.

\section{List of Figures}

Fig. 1 Plan of the Jerónimos Monastery with schematic location of the High Choir.

Fig. 2. High Choir: (a) plan of the roof showing the ribs (the vault under study is shaded); (b) front view; (c) side view; (d) vault intrados.

Fig. 3. (a) Plan of the south dome (under study); (b) niche in the west wall.

Fig. 4. (a) Transverse section of the High Choir; (b) column section.

Fig. 5. Cross-section of the arches: (a) east arch; (b) north arch.

Fig. 6. (a) Plan of the ribs' distribution; (b) ribs' cross-section; (c) approximated cross-sections.

Fig. 7. Refined model: (a) ribs; (b) slabs and ribs; (c) filler layer.

Fig. 8. Simplified model.

Fig. 9. Model boundary conditions.

Fig. 10. Vault vertical deformation and displacement contour under its self-weight (ribs, slabs and filler): (a) refined model; (b) simplified model.

Fig. 11. Structure response under its self-weight: (a) load-vertical displacement diagram; (b) deformed shape at the ultimate load step.

Fig. 12. Principal strains and stresses in the vault under its self-weight: (a) tensile strains at the vault intrados; (b) tensile strains at the vault extrados; (c) compressive stresses at the vault intrados; (d) compressive stresses at the vault extrados. Stresses in $\mathrm{kN} / \mathrm{m}^{2}$.

Fig. 13. Effect of masonry compressive strength on the structure response under its self-weight: (a) vertical displacement of the vault key; (b) horizontal displacement of the column head.

Fig. 14. Effect of masonry compressive strength on the structure response under its self-weight and new organ: (a) load factor-vertical displacement of the vault key; (b) load factor-horizontal displacement of the column head.

Fig. 15. Effect of the ribs' cross-section on the structural response (only self-weight is considered): (a) ribs' extended cross-sections; (b) load factor-vertical displacement curves.

Fig. 16. Load factor-horizontal displacement diagrams obtained from pushover analysis (selfweight + seismic load) obtained at: (a) end of the north arch; (b) column head.

Fig. 17. Load factor-horizontal displacement diagrams obtained from pushover analysis (selfweight + new organ + seismic load) obtained at: (a) end of the north arch; (b) column head.

Fig. 18. Principle strains and stresses at failure load for reference model (self-weight + new organ + seismic load): (a) tensile strains at the vault intrados; (b) tensile strains at the vault extrados; (c) compressive stresses at the vault intrados; (d) compressive stresses at the vault extrados. Stresses in $\mathrm{kN} / \mathrm{m}^{2}$.

Fig. 19. Effect of the ribs' cross-section on the structure response (self-weight + new organ + seismic load). 
Table 1. Vault vertical deformation in refined and simplified models.

\begin{tabular}{lcc}
\hline \multirow{2}{*}{ Elements } & \multicolumn{2}{c}{$\delta_{\mathrm{z}, \max }(\mathrm{mm})$} \\
\cline { 2 - 3 } considered & Refined & Simple model \\
& model & \\
\hline Ribs & 1.18 & 1.4 \\
\hline Ribs and slabs & 2.01 & 1.84 \\
\hline Ribs, slabs and & & 1.96 \\
filler layer & 1.63 & \\
\hline
\end{tabular}




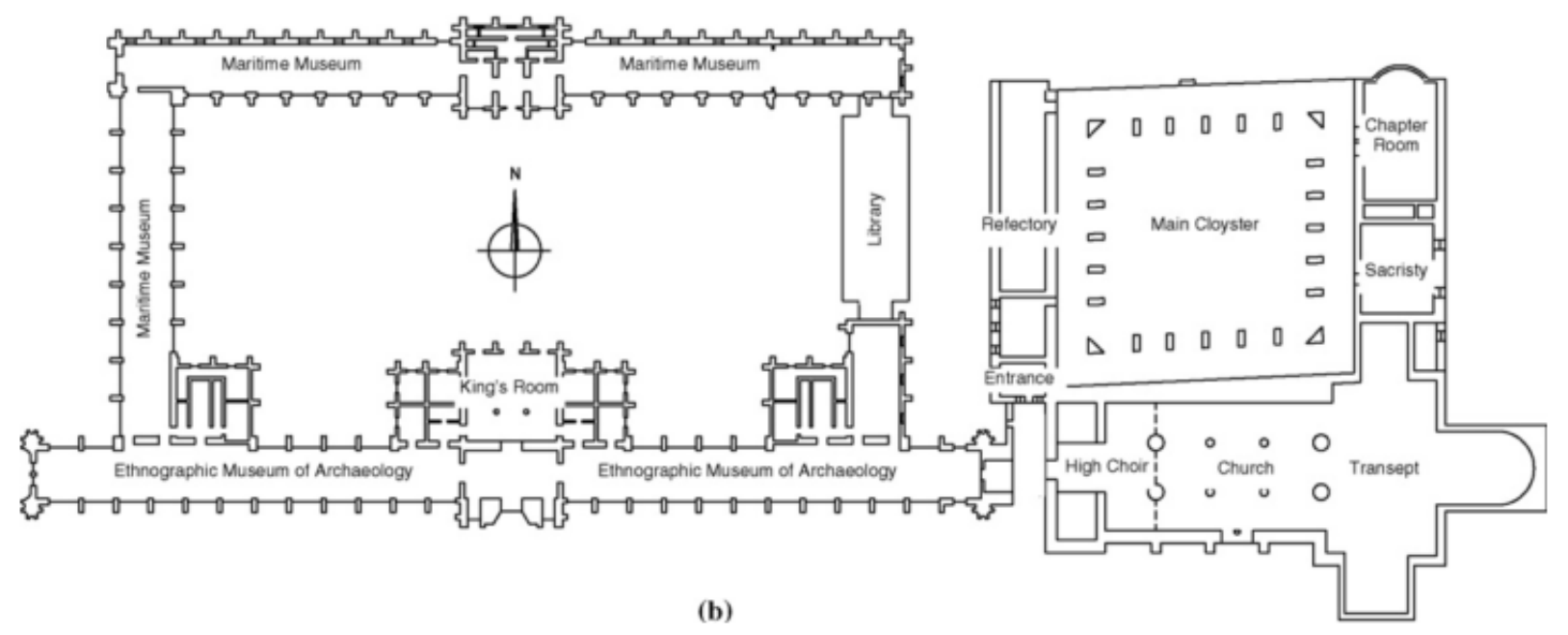

Fig. 1 Plan of the Jerónimos Monastery with schematic location of the High Choir. 


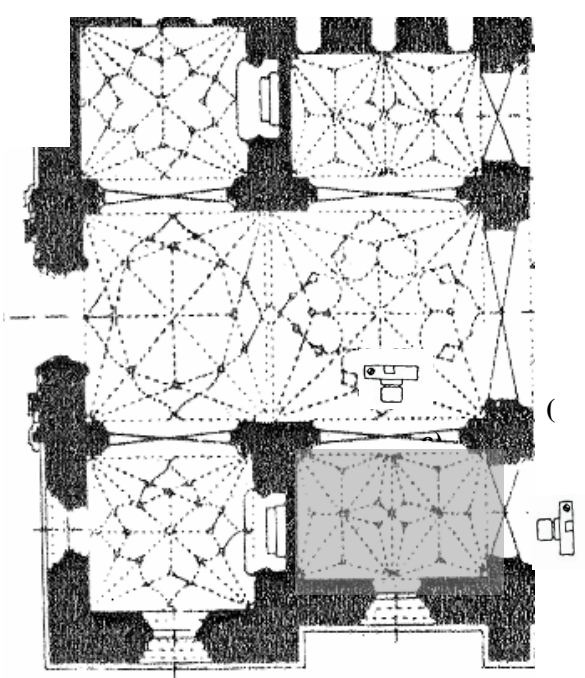

(a)

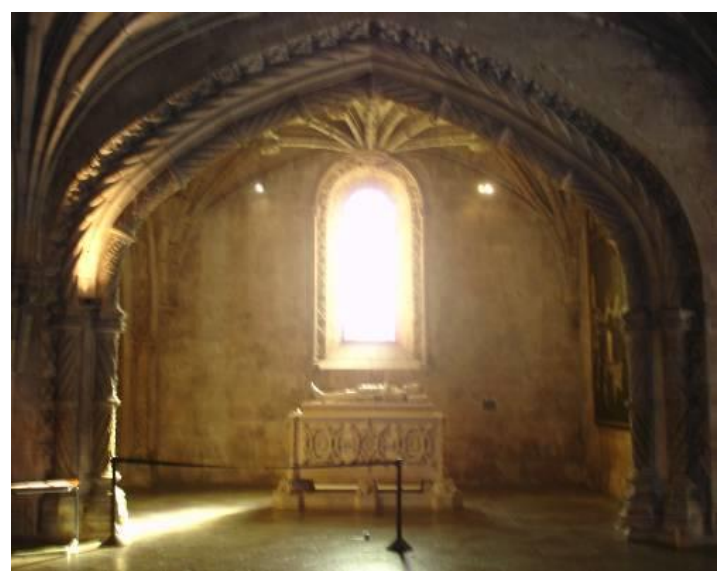

(c)

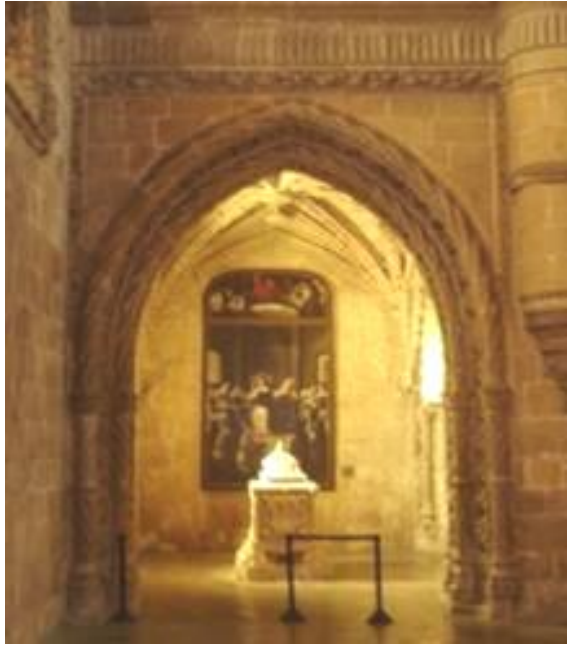

(b)

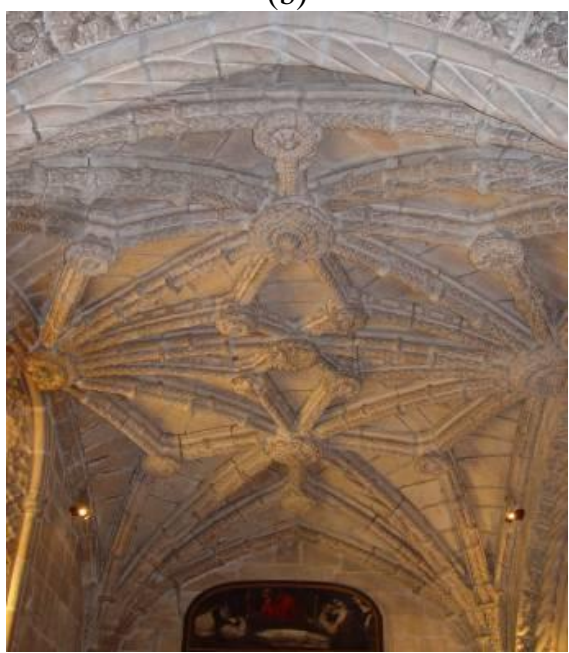

(d)

Fig. 2. The High Choir: (a) plan of the roof showing the ribs (the vault under study is shaded); (b) front view; (c) side view; (d) vault intrados. 


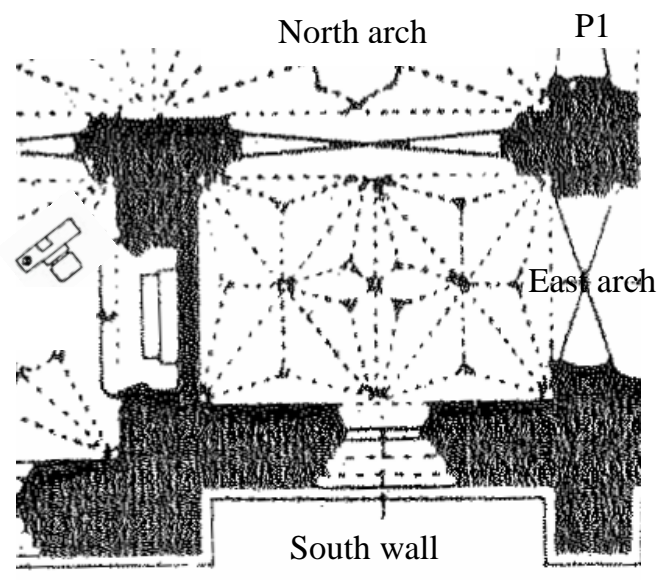

(a)

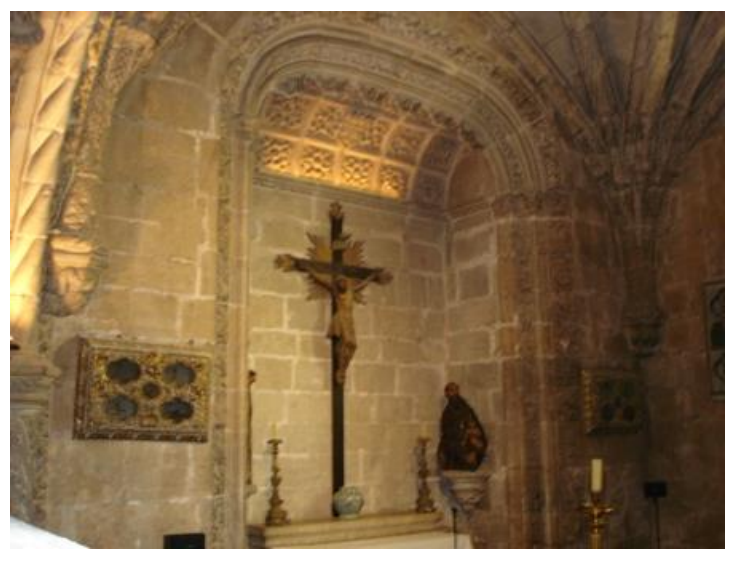

(b)

Fig. 3. (a) Plan of the south dome (under study); (b) niche in the west wall. 


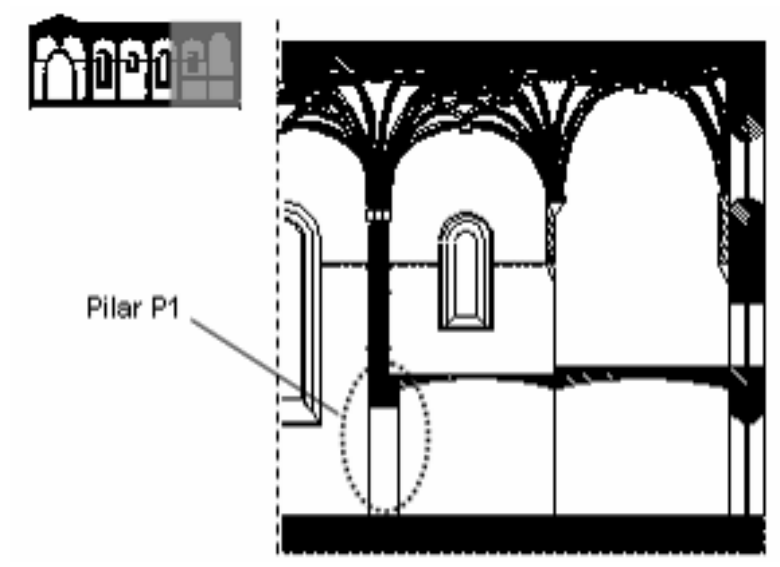

(a)
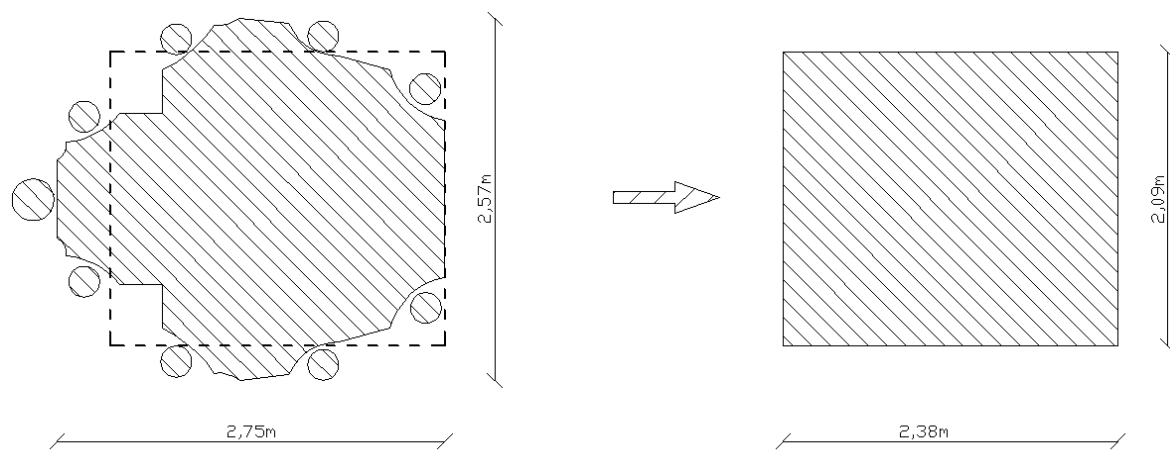

(b)

Fig. 4. (a) Transverse section of the High Choir; (b) column section. 

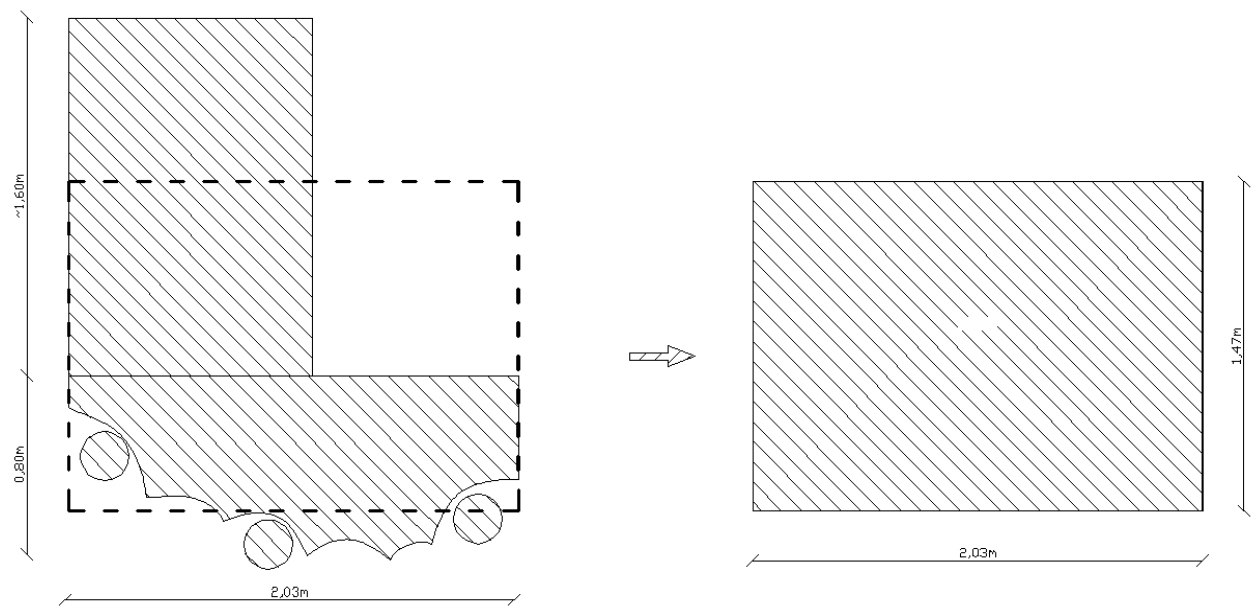

(a)
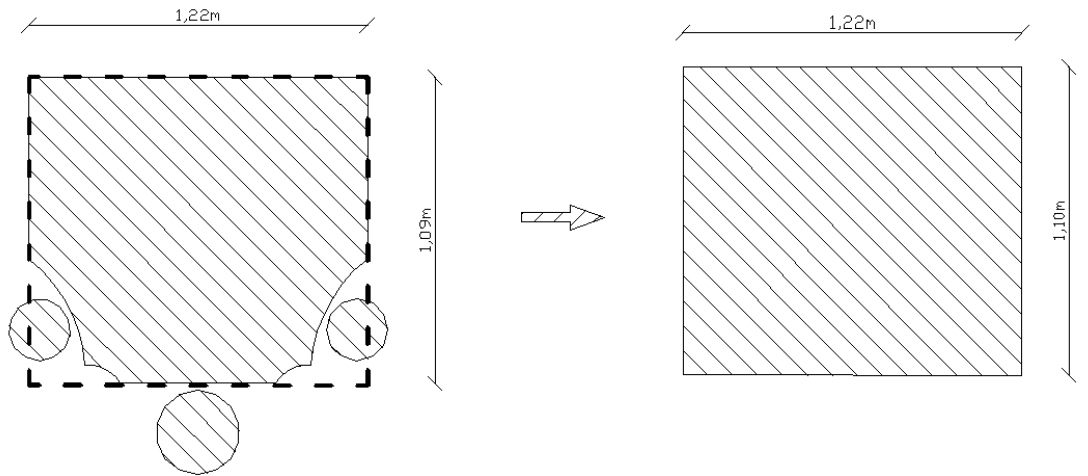

(b)

Fig. 5. Cross-section of the arches: (a) east arch; (b) north arch. 

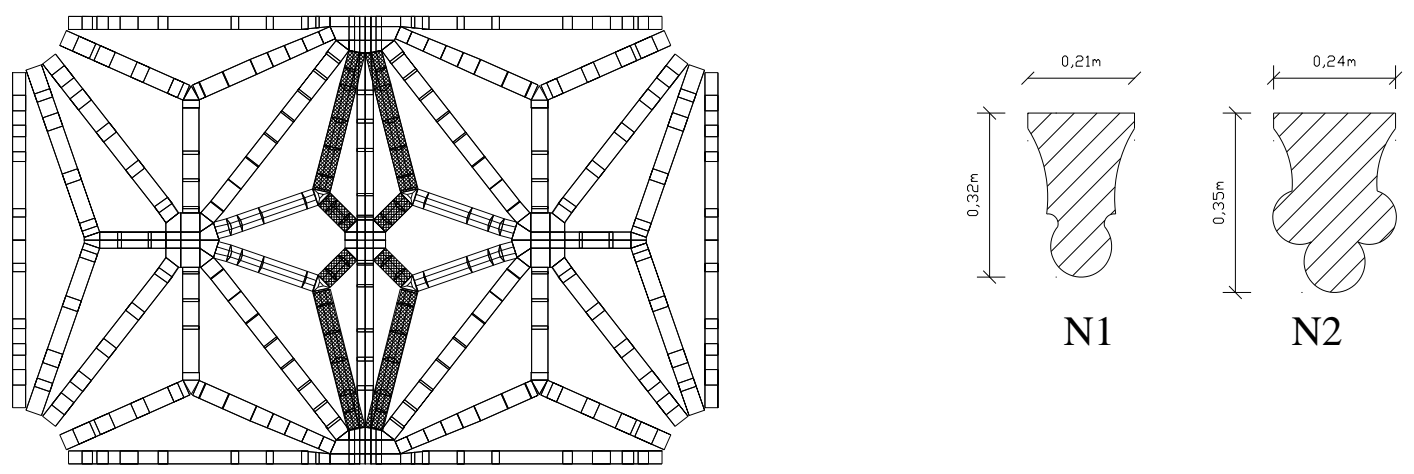

(a)
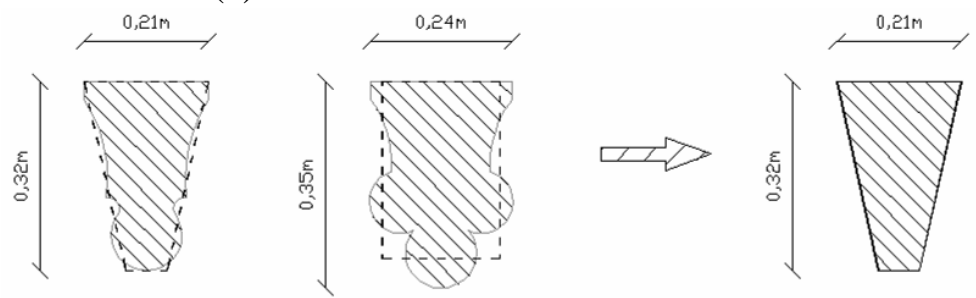

(b)

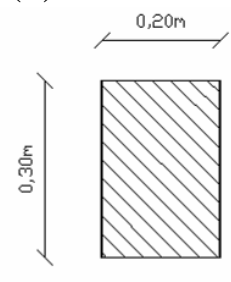

(c)

Fig. 6. (a) Plan of the ribs' distribution; (b) ribs' cross-section; (c) approximated cross-sections. 


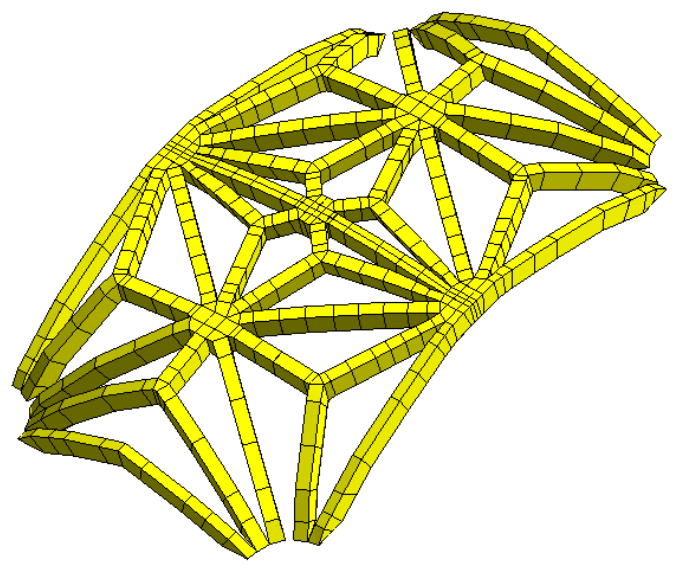

(a)

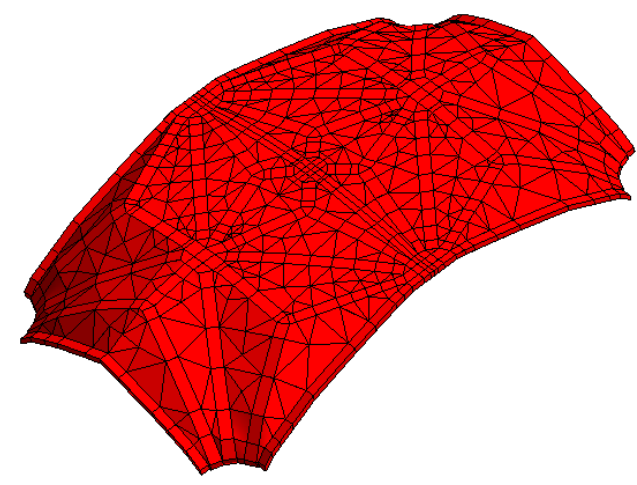

(b)

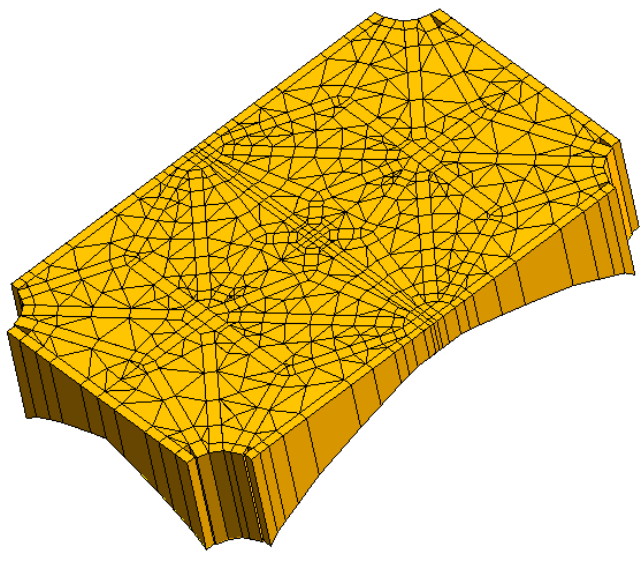

(c)

Fig. 7. Vault refined model: (a) ribs; (b) slabs and ribs; (c) filler layer. 

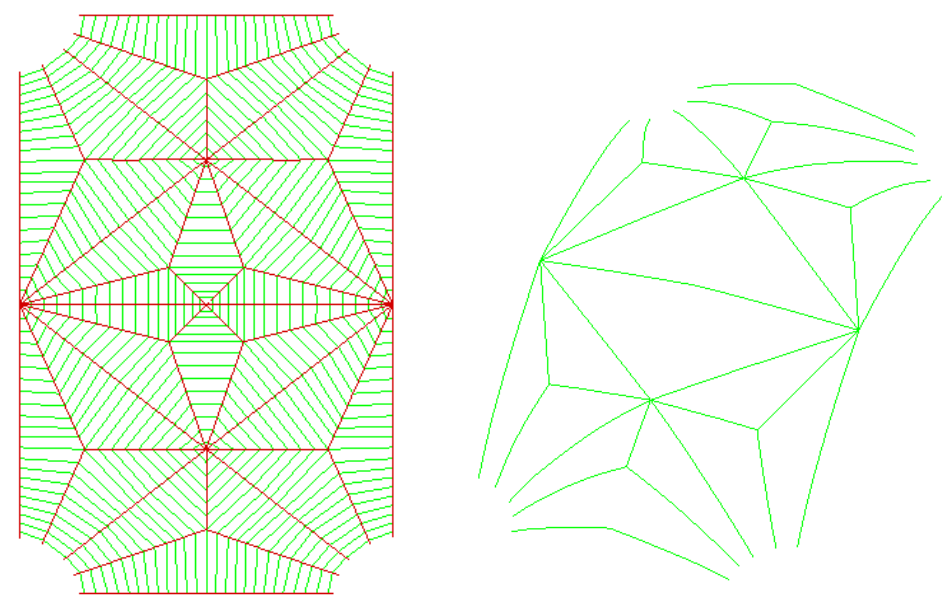

Fig. 8. Vault simplified model. 


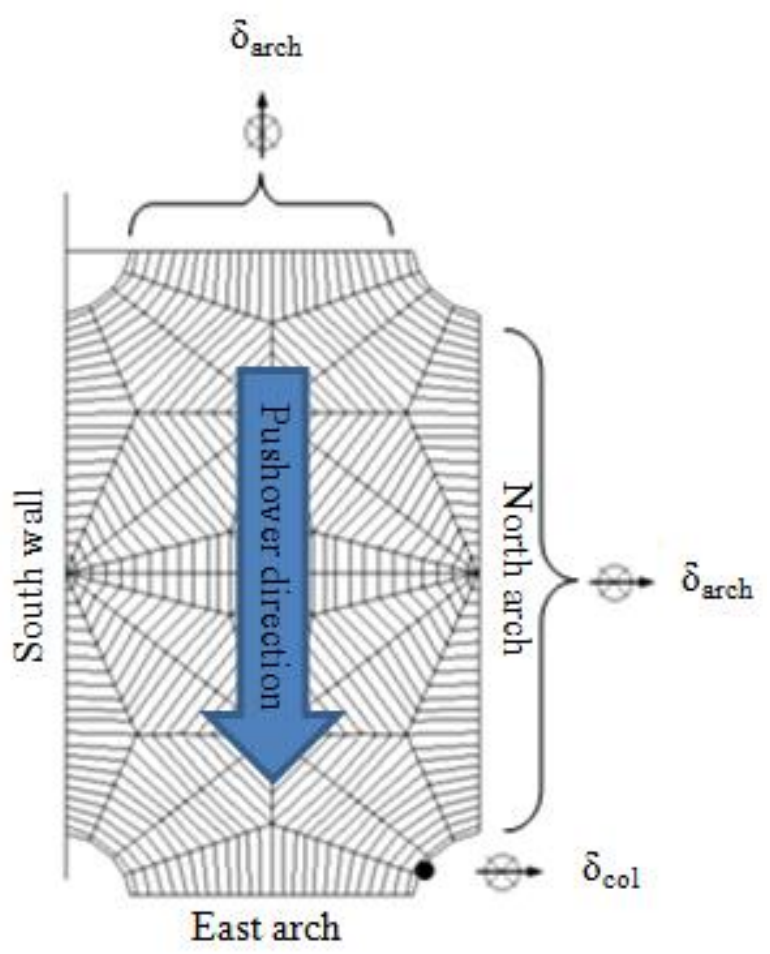

Fig. 9. Model boundary conditions. 


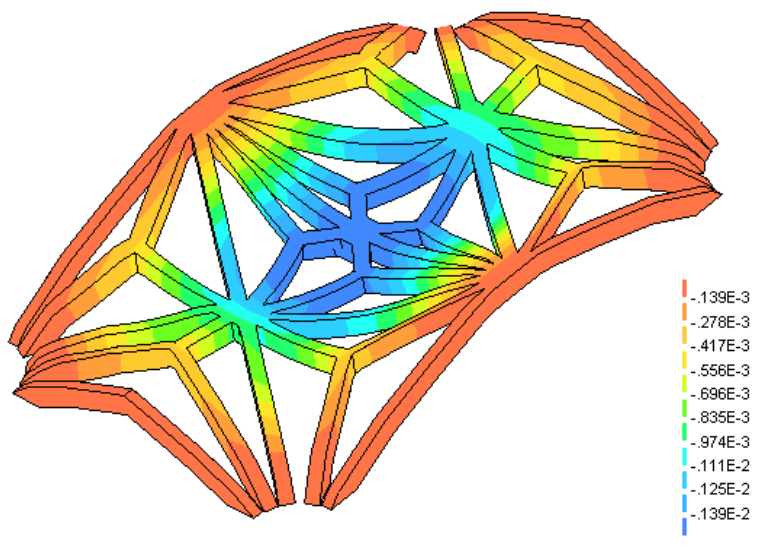

(a)

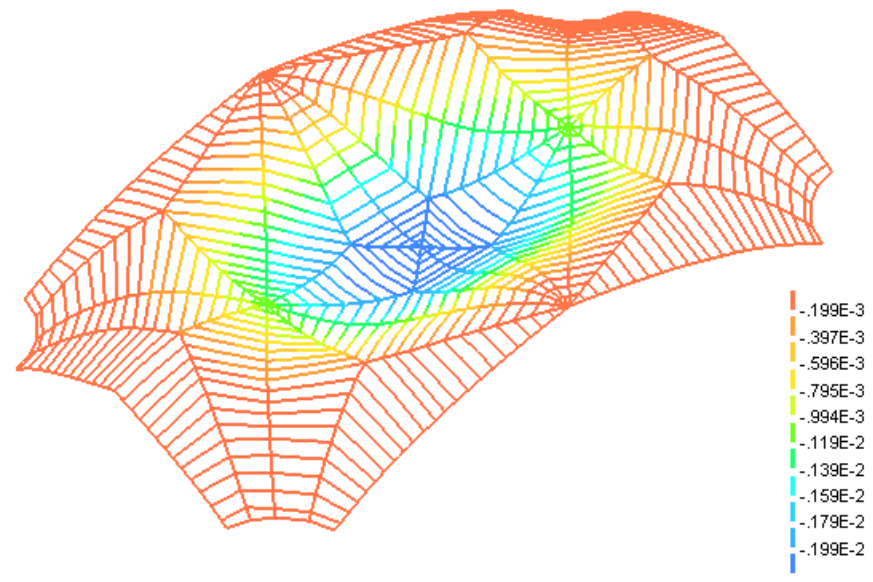

(b)

Fig. 10. Vault vertical deformation and displacement contour under its self-weight (ribs, slabs and filler): (a) refined model; (b) simplified model. 


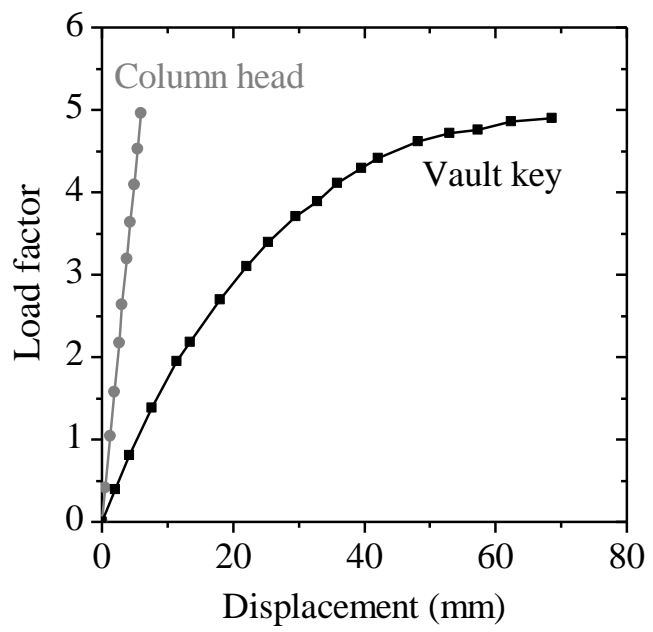

(a)

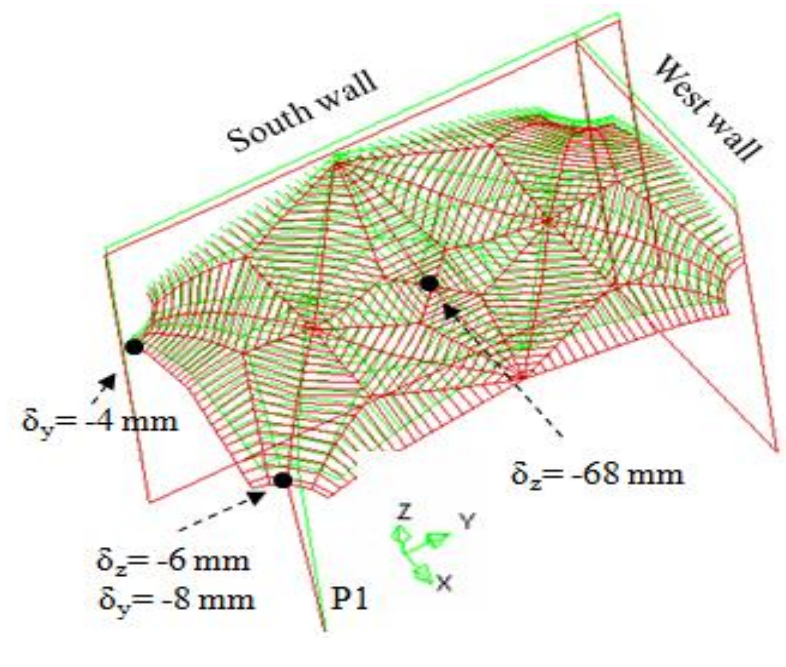

(b)

Fig. 11. Structure response under its self-weight: (a) load-vertical displacement diagram; (b) deformed shape at the ultimate load step. 


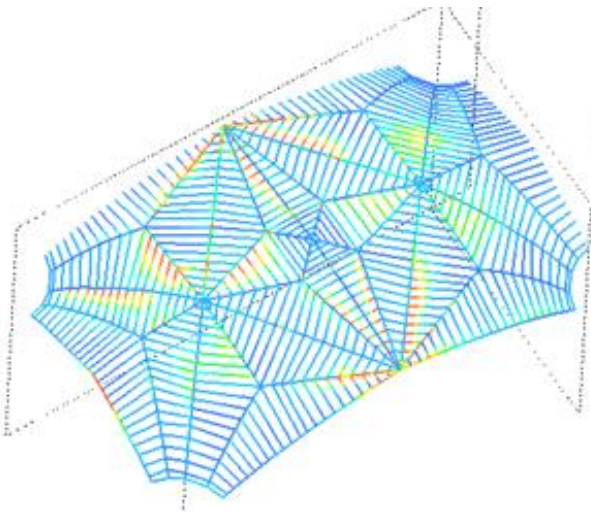

(a)

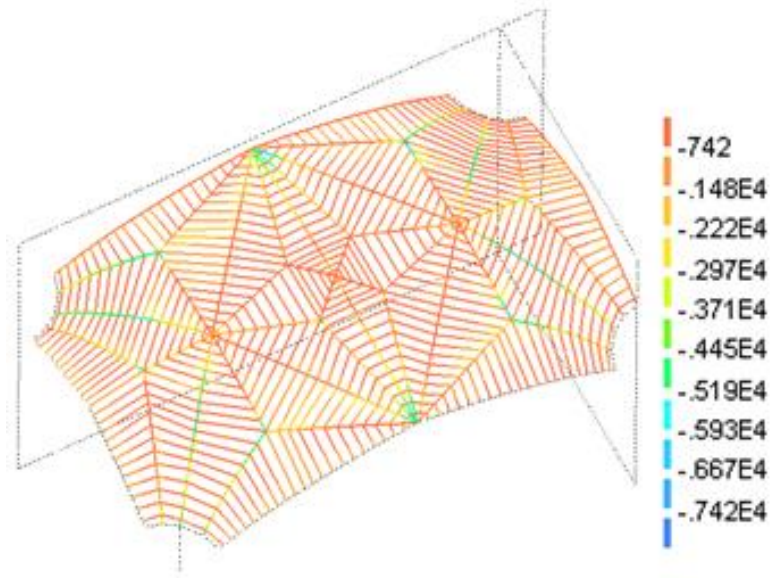

(c)

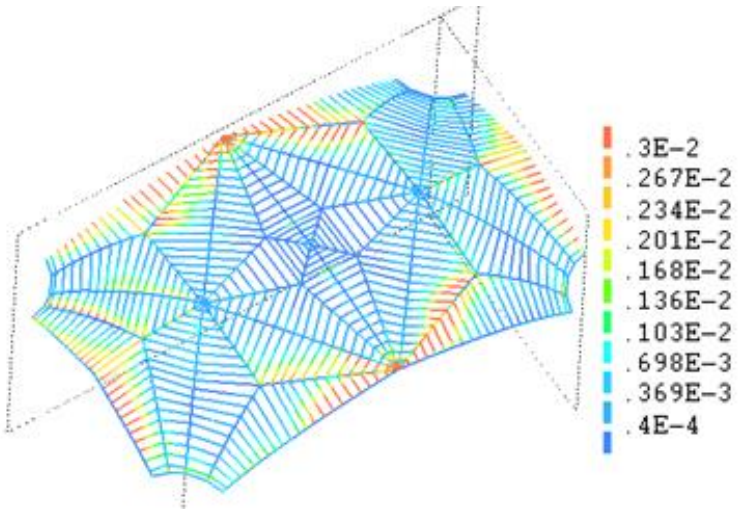

(b)

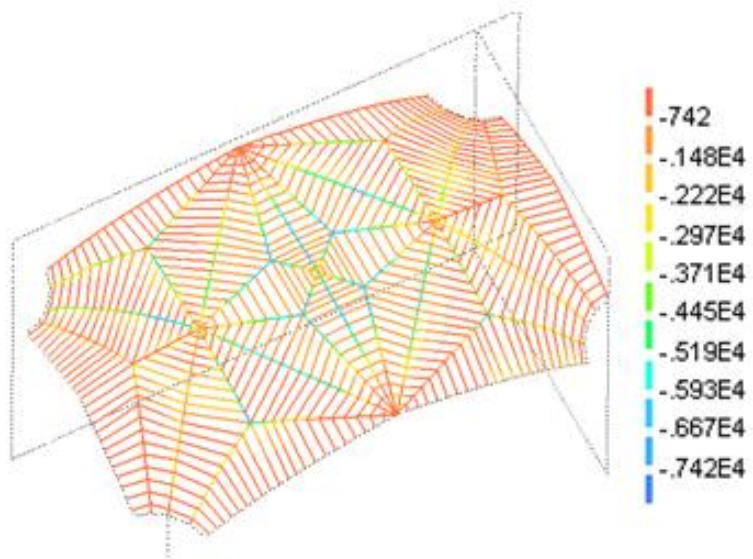

(d)

Fig. 12. Principal strains and stresses in the vault under its self-weight: (a) tensile strains at the vault intrados; (b) tensile strains at the vault extrados; (c) compressive stresses at the vault intrados; (d) compressive stresses at the vault extrados. Stresses in $\mathrm{kN} / \mathrm{m}^{2}$. 


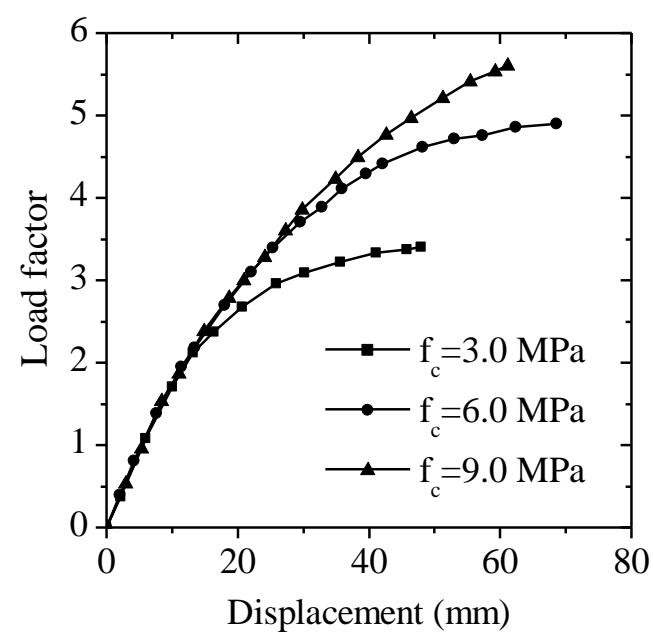

(a)

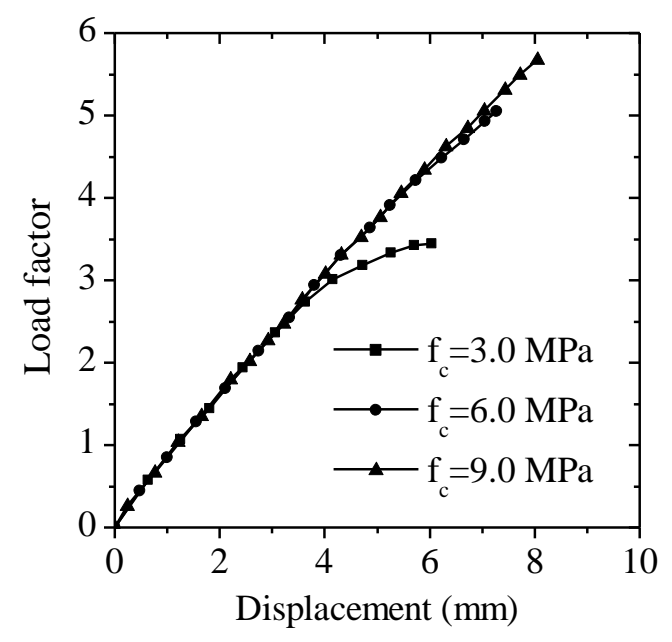

(b)

Fig. 13. Effect of masonry compressive strength on the structure response under its self-weight: (a) vertical displacement of the vault key; (b) horizontal displacement of the column head. 


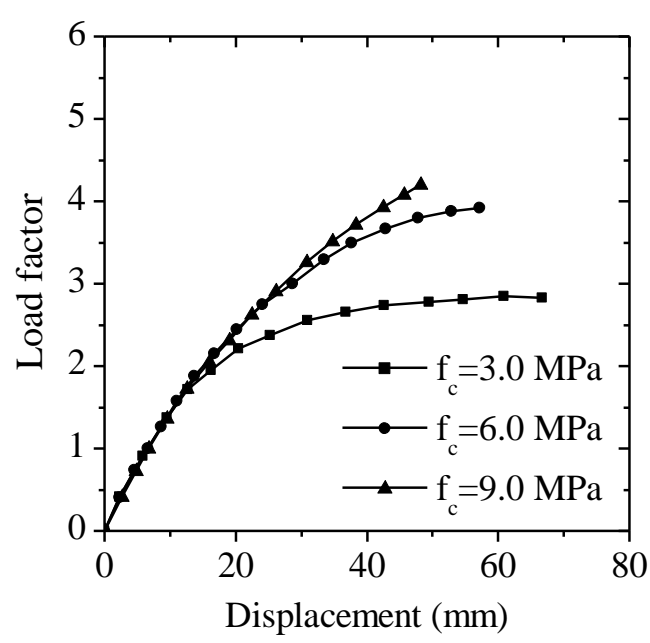

(a)

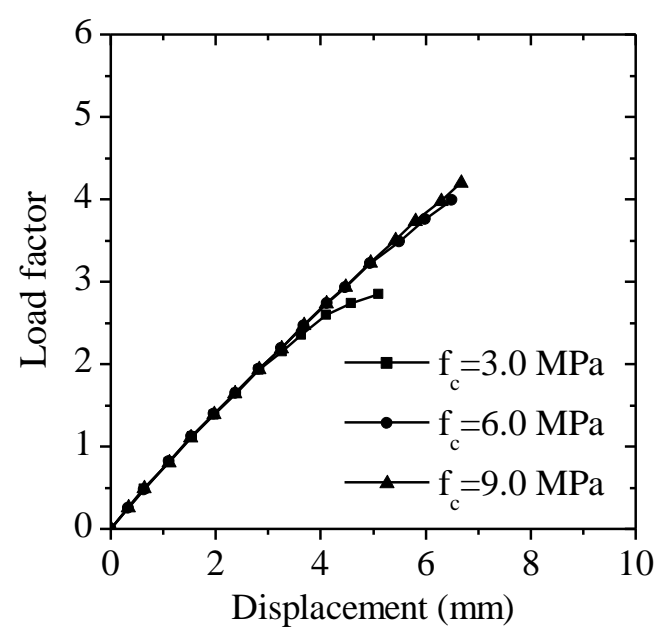

(b)

Fig. 14. Effect of masonry compressive strength on the structure response under its self-weight and new organ: (a) load factor-vertical displacement of the vault key; (b) load factor-horizontal displacement of the column head. 

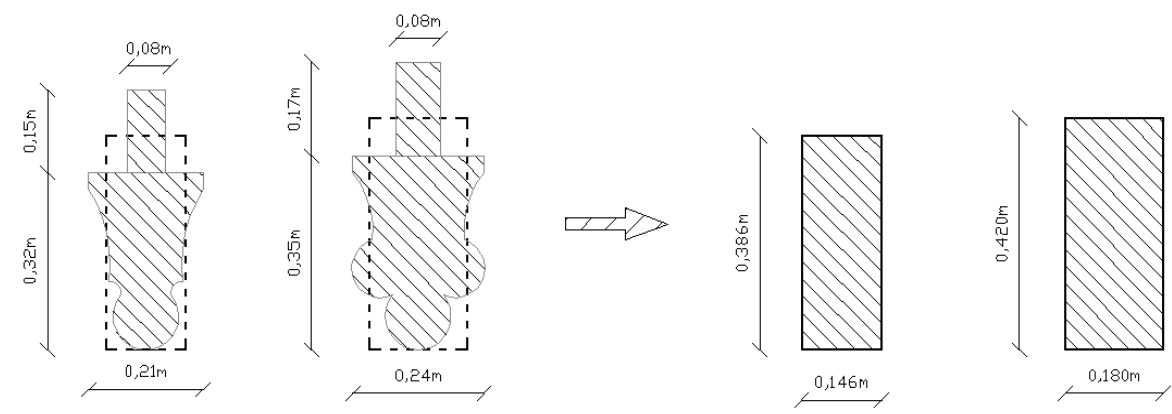

(a)

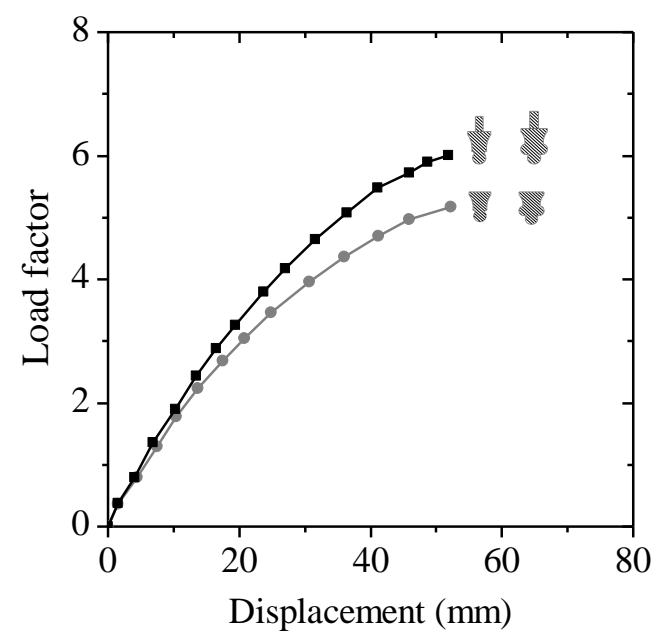

(b)

Fig. 15. Effect of the ribs' cross-section on the structural response (only self-weight is considered): (a) ribs' extended cross-sections; (b) load factor-vertical displacement curves. 


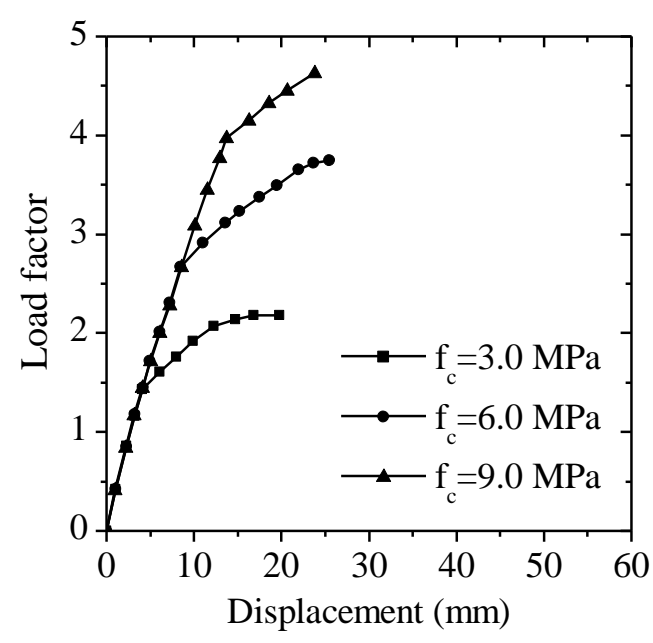

(a)

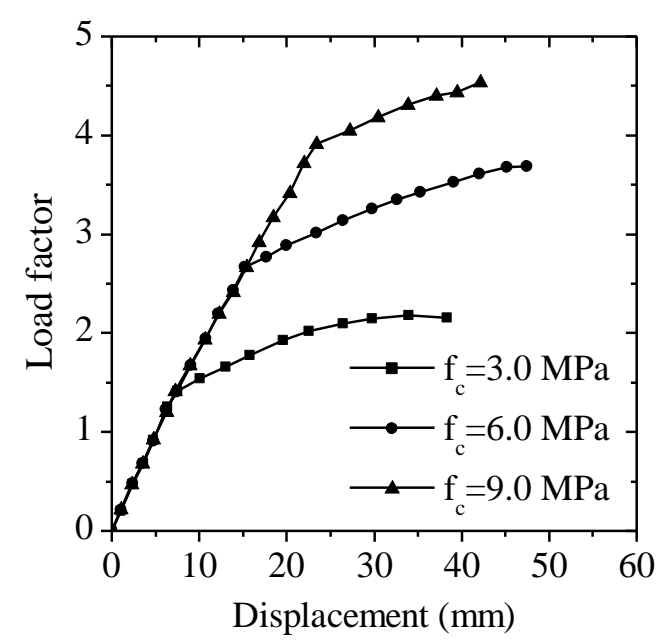

(b)

Fig. 16. Load factor-horizontal displacement diagrams obtained from pushover analysis (selfweight + seismic load) obtained at: (a) end of the north arch; (b) column head. 


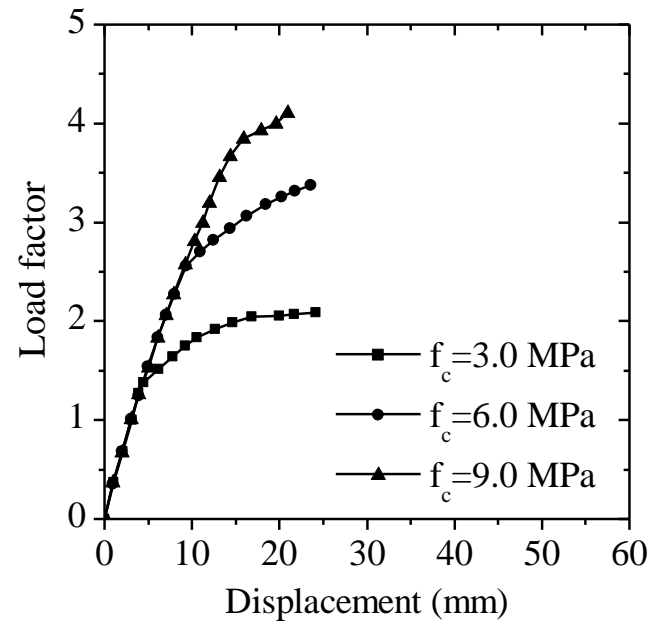

(a)

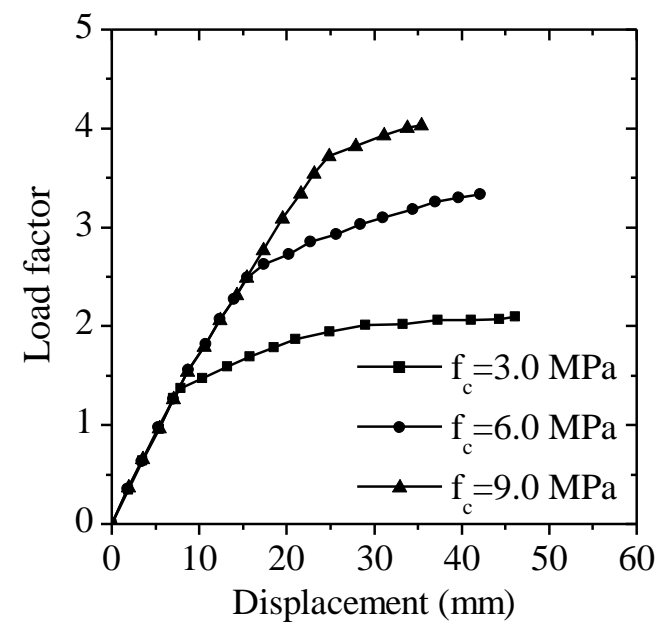

(b)

Fig. 17. Load factor-horizontal displacement diagrams obtained from pushover analysis (selfweight + new organ + seismic load) obtained at: (a) end of the north arch; (b) column head. 


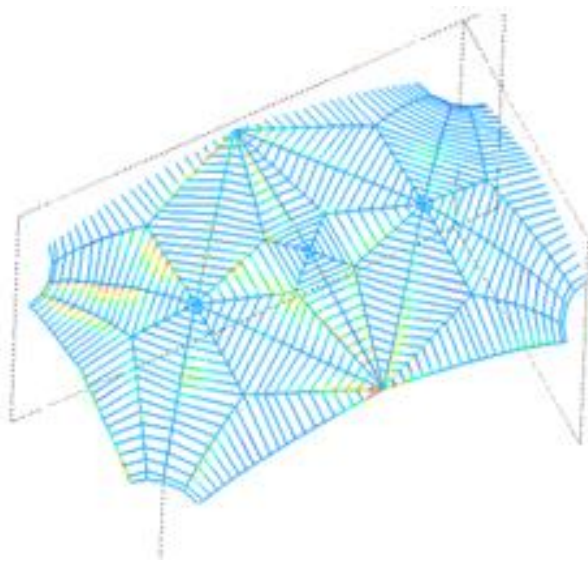

(a)

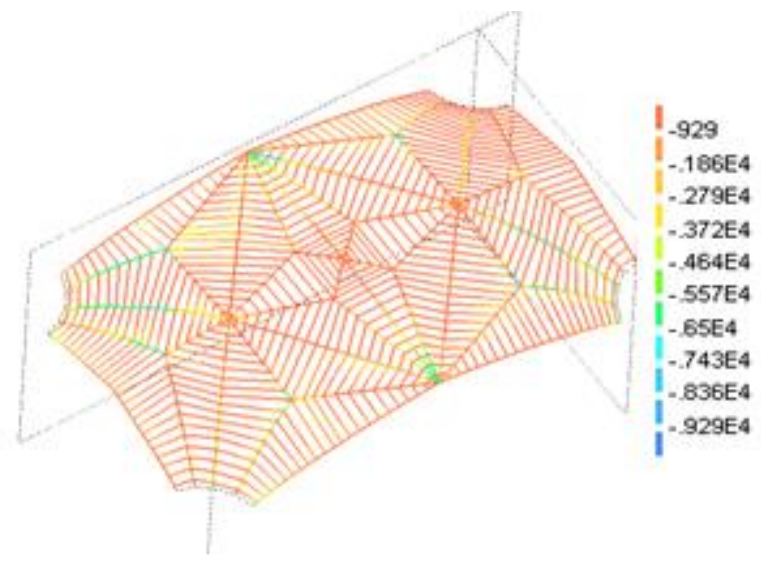

(c)

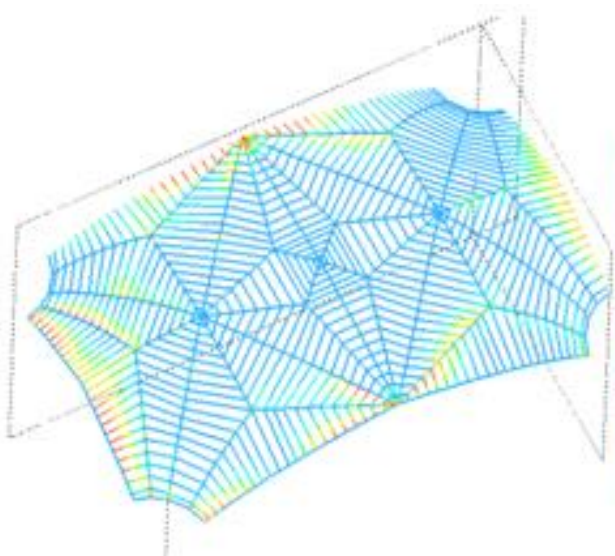

1. $1 \mathrm{E}-1$ . $889 \mathrm{E}-2$ $.778 \mathrm{E}-2$ $667 \mathrm{E}-2$ $556 \mathrm{E}-2$ 445E-2 . $334 \mathrm{E}-2$ $.223 \mathrm{E}-2$ $.112 \mathrm{E}-2$ $.152 \mathrm{E}-4$

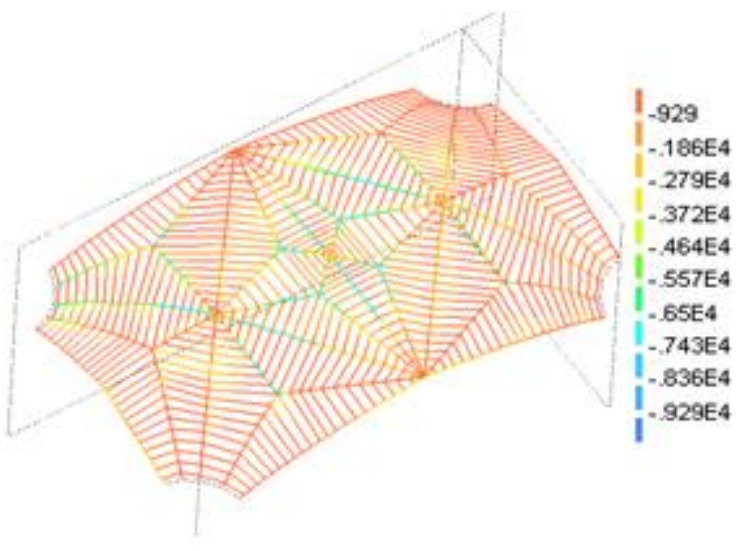

(d)

Fig. 18. Principle strains and stresses at failure load for reference model (self-weight + new organ + seismic load): (a) tensile strains at the vault intrados; (b) tensile strains at the vault extrados; (c) compressive stresses at the vault intrados; (d) compressive stresses at the vault extrados. Stresses in $\mathrm{kN} / \mathrm{m}^{2}$. 


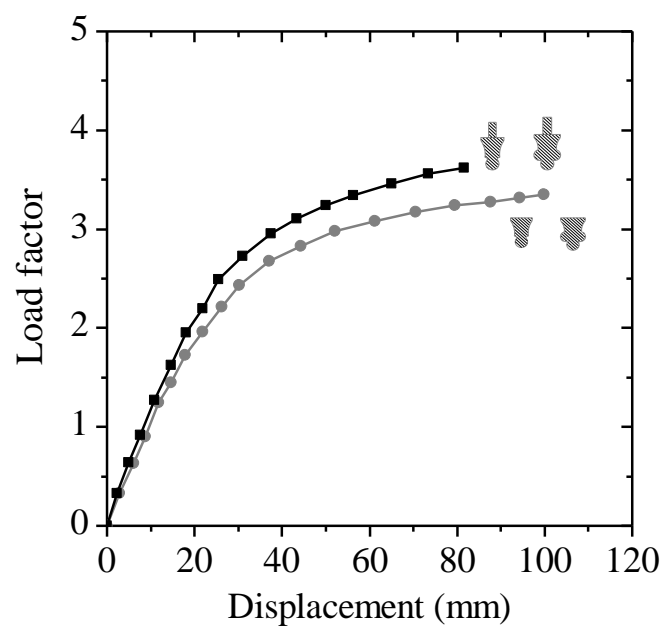

Fig. 19. Effect of the ribs' cross-section on the structure response (self-weight + new organ + seismic load). 